\section{The Role of the Private Sector in Health Care Reform}

In his commentary in the January 2012 issue of JNCCN, David Hohn, MD, ${ }^{1}$ laid out many of the opportunities, concerns, and uncertainties related to health care reform and the potential impact on cancer centers, physicians, and patients. By the time you read this, we will probably know if the Supreme Court upheld the Patient Protection and Affordable Care Act (PPACA) or ruled the entire Act or portions of it to be unconstitutional.

Regardless of the Supreme Court's decision, however, the landscape for health insurance and medical care has already been unalterably changed and will continue to evolve. Especially if PPACA is overturned, the private sector, and self-funded employers in particular, will play an important role in the further evolution of the health care system. Self-funded employers choose to assume financial responsibility and risk of paying their beneficiaries' medical and pharmacy plan expenses, rather than transferring that responsibility to a managed care organization or insurance company. Self-funded plans are not subject to state insurance mandates related to benefits and coverage but are instead governed by Federal ERISA (Employee Retirement Income Security Act ${ }^{2}$ ) legislation. Self-funding gives employers increased flexibility in designing their employee benefits, and they have used it. The private sector serves as an innovation laboratory as employers, managed care organizations, and others address the challenges of cost, quality, and productivity, and design benefits to meet their needs and the needs of beneficiaries. This includes, of course, medical and pharmacy coverage, but also disability and employee assistance programs and programs to prevent and manage illnesses, and promote "wellness."

NCCN only recently became involved in public policy issues when, in 2008, NCCN sought and achieved recognition of the NCCN Drugs \& Biologics Compendium (NCCN Compendium) as the basis for coverage decisions for Medicare beneficiaries. Since then, NCCN has taken a greater role in influencing public policy on issues that affect cancer care. NCCN is taking a leading role in developing policy in the private sector as well, by collaborating with managed care organizations, large employers, and employer coalitions.

NCCN's collaboration with the National Business Group on Health to develop An Employer's Guide to Cancer Treatment \& Prevention (the Guide) is an example of this, and is the most extensive venture to date. It is also arguably the most likely to have a farreaching impact. The Guide provides practical, ready-to-implement recommendations and tools to help employers design and implement cancer-related employee benefits. It addresses cancer-related issues across the benefit continuum, including wellness, prevention, and screening; medical and pharmacy benefit plans; disability and employee assistance plans; family medical leave and caregiver needs; survivorship; and end-oflife care. Recommendations in the Guide are supported by evidence and insights from a wide range of sources, including the NCCN Clinical Practice Guidelines in Oncology (NCCN Guidelines) and NCCN Compendium. Through adopting benefit recommendations in the Guide, employers can be more confident that their cancerrelated benefit dollars are being invested wisely and will meet the needs of beneficiaries.

Some of the recommendations likely to have an important and far-reaching impact relate to:

Medical plan coverage for:

- Diagnosis, treatment, and second-opinion services from a wide range of cancer care specialists, both in the community and in academic centers, including NCIdesignated cancer centers and comprehensive cancer centers

- Routine costs of care when enrolled in a well-designed cancer clinical trial, including coverage when the individual is enrolled in hospice

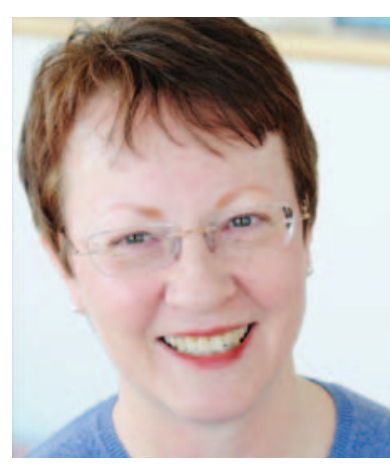

Elizabeth Danielson, MHA

Elizabeth Danielson, MHA, is

Director of Payor Relations at NCCN. Ms. Danielson is responsible for developing, maintaining, and expanding working relationships between NCCN and managed care organizations, employers, and other payor organizations nationwide.

Currently Ms. Danielson is the lead NCCN representative on a project with the National Business Group on Health (NBGH) that is addressing issues related to cancer benefits and services across the continuum of care. The tools developed as part of this 3-year project can be readily applied to many aspects of the self-funded employer's benefit life cycle, including benefit planning and implementation; request for proposal (RFP) development, review, and scoring; vendor management; and plan administration and evaluation. Ms. Danielson has 25 years of experience in the health care industry. Prior to joining NCCN in 2008, Ms. Danielson was Director of Cancer Programs at OptumHealth. While at OptumHealth, she was responsible for developing, launching, and selling the first cancer "centers of excellence" program and was key in developing and launching a cancer case management program. 
Danielson

- Hospice when the individual has an estimated life expectancy of 12 months or less (rather than the usual 6 months)

- Genetic testing, and biomarker and molecular testing, consistent with recommendations in NCCN Guidelines

- Fertility preservation services and dental services under specific circumstances related to cancer treatment

Medical and/or pharmacy plan coverage:

- With reasonable levels of patient cost-sharing for drugs and biologics

- For drugs and biologics in cancer care based on recommendations in the NCCN Compendium

- Parity of patient cost-sharing between the medical and pharmacy benefit plans

To view the entire toolkit associated with this project, visit www.businessgrouphealth.org and click on "Cancer" in the Hot Topics list. You can also click on An Employer's Guide to Cancer Treatment and Prevention: Tool 2: Plan Design \& Assessment Tool at businessgrouphealth.org/pdfs/CancerTool2.pdf.

Information has been disseminated through webinars and public presentations and by making all components of the Guide available in the public domain at no cost. Employers, benefit consultants, managed care organizations, and pharmacy benefit plans have all shown a high level of interest in the project, with a combined total of almost 47,000 document views and downloads between July 2011 and March 2012. Adoption of the benefit recommendations is already occurring, which we believe will benefit employers, patients, and cancer care providers alike. Physicians may be interested in understanding the project because it will affect their patients' benefits and coverage. State medical societies and other groups may be able to influence employers to adopt the recommendations by providing real-life examples of how offering these benefits can make a different for patients.

Funding is being sought for an actuarial analysis that will quantify the net cost or net savings that can be expected if the benefits are adopted by employers. We are hopeful that funding will be obtained and the analysis published in 2013, as the project's impact is likely to increase with these results. We expect the cost of implementing the recommendations to be modest; in fact, the recommendations may, in some cases, reduce cost of care.

This project has been described as "private sector health care reform at its best." By articulating recommendations that are driven by evidence and are accompanied by estimates of likely costs or savings, NCCN and the National Business Group on Health are introducing a model that can influence coverage for the estimated $59 \%$ of Americans younger than 65 years who receive employer-sponsored health benefits. ${ }^{3}$ The recommendations may be adopted by managed care organizations on behalf of employers who do not self-fund and by CMS. They can also influence what is included in "essential health benefits" for health care exchanges. Finally, the Guide serves as a model that can be followed in developing benefit recommendations for other costly and complex health conditions.

\section{References}

1. Hohn DC. Health care reform and its implications for the academic cancer center. J Natl Compr Canc Netw 2012;10:130-132.

2. US Department of Labor. Employee Retirement Income Security Act-ERISA. Available at www. dol.gov/dol/topic/health-plans/erisa.htm. Accessed June 7, 2012.

3. Gould E. A decade of declines in employer-sponsored health insurance coverage. Economic Policy Institute. Available at www.epi.org/publication/bp337-employer-sponsored-health insurance. Published February 23, 2012. Accessed June 7, 2012. 